\title{
Mothers Adherence to Global Infant and Young Child Feeding Strategies in Ketu North District, Volta Region - Ghana
}

\author{
Prince Kubi Appiah, (MPH) \\ Wilson Mensah Dzata, (BPH) \\ Department of Family and Community Health, School of Public Health, \\ University of Health and Allied Sciences, Ho, Ghana \\ Duut Abdulai Bonchel, (MPhil) \\ Department of Social Work, University of Ghana, Legon, Accra, Ghana \\ Anang Rhoda Naa Korklu, (BPH) \\ Doe Jessica Naa Ayeley, (BPH) \\ Department of Family and Community Health, School of Public Health, \\ University of Health and Allied Sciences, Ho, Ghana \\ Georgina Agartha Fenu, (BPH) \\ Department of Epidemiology and Biostatistics, School of Public Health, \\ University of Health and Allied Sciences, Ho, Ghana \\ Timay Ibrahim Abdul-Rahman, (BPH) \\ Department of Population and Behavioural Sciences, School of Public \\ Health, University of Health and Allied Sciences, Ho, Ghana
}

Doi: 10.19044/esj.2017.v13n30p183 URL:http://dx.doi.org/10.19044/esj.2017.v13n30p183

Abstract

Background: Infant and young child nutrition has been engaging the attention of scientists and governments over the years. Their feeding practices comprise both breastfeeding as well as complementary feeding which have major role in determining the nutritional status of the child, therefore, there has been a well-established link between malnutrition and infant feeding. Children are the future of the world and yet the most vulnerable population, with some 6.6 million children dying before their fifth birthday globally. Studies have shown that poor breastfeeding and complementary feeding practices, coupled with high rates of morbidity from infectious diseases are the primary causes of malnutrition and death in the first two years of life. Ketu-North district noted that even though nutrition and health programmes were in place, breastfeeding coverage has been between $53 \%$ in 2013 and $69 \%$ in 2015 . This study sought to assess mothers or caregivers adherence to Infant and Young Child Feeding (IYCF) practices 
in Ketu North District of the Volta Region in Ghana. Method: A crosssectional study among mothers/caregivers with children 0-24 months in the district. Multistage sampling techniques was used to select 518 respondents. A semi-structured questionnaire was used to conduct face-to-face interviews. Statistical software Epi Data version 3.1 and Stata version 12.1 were used for data entry and analysis respectively. Descriptive statistics was presented in tables and graphs. Beyond descriptive statistics, associations between the outcome and predictor variables were analysed using Pearson chi-square and logistics regression. P-value $<.05$ was considered as statistically significant. Findings: Respondents had a mean age of 25.6 years $( \pm 3.6$ SD). Only $8.7 \%$ of the mothers adhered to IYCF strategies with practices of exclusive breastfeeding, complementary feeding, hygiene and sanitation practices, meal variety, and meal frequency being $57.9 \%, 38.0 \%, 16.2 \%, 37.1 \%$, and $33.2 \%$ respectively. Ethnicity $(p<.000)$, age of child $(p=.032)$, employment $(p=.041)$ and level of education $(p=.042)$ were found to be associated with adherence to IYCF strategies. Conclusions: Adherence to infant and young child feeding practices were not encouraging in the district therefore the district health management team need to strengthen health education and implement other behaviour change interventions to improve on the adherence to feeding strategies. Further studies should be conducted to assess factors influencing the low adherence to the feeding strategies in the district.

Keywords: Exclusive breastfeeding, complementary feeding, mothers/caregivers, Ketu North District

\section{Introduction}

Infant and young child nutrition has been engaging the attention of scientists and governments over the years (Ramji, 2009). Infant and young child feeding practices comprise both the breastfeeding as well as the complementary feeding and have major role in determining the nutritional status of the child (Lenggogeni, 2016). The link between malnutrition and infant feeding has been well established (Ramji, 2009).

The first two years of life are critical stages for child growth and development, and any damage caused by nutritional deficiencies during this period could lead to impaired cognitive development, compromised educational achievement and low economic productivity (Granthammcgregor et al., 2007; Oddy et al., 2003). Studies have shown that poor breastfeeding and complementary feeding practices, coupled with high rates of morbidity from infectious diseases are the primary causes of malnutrition in the first two years of life (Grantham-mcgregor et al., 2007). However, 
under-nutrition is persistent in low and middle income countries, with Africa and Asia being the most affected (Bain et al., 2013)

Globally, nearly one in four children (165 million or 26\%) are affected by the most severe life-long consequences of under-nutrition (stunting) (WHO, 2010). Malnutrition underlies majority of under five deaths, $70 \%$ of which occur in the first year of life with estimated 32\% (186 million) children aged below five years in developing countries stunted and about 10\% (55 million) wasted (Satija et al 2015; WHO, 2010). In 2010, one out of thirteen children in Ghana died before their fifth birthday mostly as a result of under-nutrition (GHS, 2010), and currently 5\% wasted, 19\% stunted, 11\% underweight, 3\% overweight or obese state (UNICEF, 2015). In 2015, 5 million children in developing countries died before their fifth birthday with over one third caused by malnutrition due to inadequate complementary feeding (Satija et al., 2015).

In 2002, World Health Assembly championed by WHO and UNICEF emphasized on Maternal Nutrition and Infant and Young Child Feeding (IYCF) to prevent and reduce child under-nutrition especially stunting which cannot be corrected after the first 1000 days of life (Lartey, 2008). Mothers/Caregivers are required to exclusively breastfeed newborns up to six months and continue breastfeeding up till two years or beyond while introducing complementary foods at six months (Finance \& Focused, 2016). However, studies have shown low compliance to these recommendations (Agbozo, Colecraft, \& Ellahi, 2015). This has led to $70 \%$ of infants in Africa facing greater risk of morbidity and mortality (AU, 2009).

According to Volta Regional Health Directorate (VRHD), there has been a reduction in underweight cases from $12.8 \%$ in 2012 to $10.5 \%$ in 2015 (VRHD, 2015) revealing little reduction in the prevalence of underweight under-nutrition over a period of five years, with breastfeeding coverage being between 53\% in 2013 and 69\% in 2015 in Ketu North district (KNHD, 2015). In the light of this, the study was conducted in Ketu North District to assess mothers/caregivers adherence to infant and young child feeding strategies.

\section{Materials and Methods \\ Study Site}

The Ketu North District is one of the 32 new districts created in Ghana in the year 2008. It was carved out of the then Ketu District by a Legislative Instrument (LI 1841 of 2008) and was inaugurated on the 29th February, 2008. The district has Four (4) health demarcated sub-districts with about 272 communities. It has its administrative capital at Dzodze, which lies about 80 kilometres south of Ho, the regional capital. Ketu North District is located between Latitude $6^{\circ} 03^{\prime} \mathrm{N}$ and $6^{\circ} 20^{\prime} \mathrm{N}$ and Longitude $0^{\circ}$ 
49'E and $1^{\circ} 05^{\prime} \mathrm{E}$. It shares boundaries with the Akatsi North District to the north, the Keta Municipality to the south-west, Republic of Togo to the east. To the south, it is bounded by the Ketu South Municipality and to the west by the Akatsi South District. The District covers a total surface area of 423.8 square kilometres representing 2.1 percent of the total land area of the Volta Region.

The population of Ketu North District, according to the 2010 Population and Housing Census, is 99,913 representing 4.7 percent of the region's total population. Males constitute $46.5 \%$ and females represent $53.5 \%$. Nearly Sixty-six percent $(65.8 \%)$ of the population is rural. The district has a sex ratio of 87.2. The population of the district is youthful (43.0\%) depicting a broad base population pyramid which tapers off with a small number of elderly persons $(6.5 \%)$. The total age dependency ratio for the District is 82.3 , the age dependency ratio for males is higher (87.3) than that of females (77.8) (GSS, 2012).

The major ethnic groups found in the District according to the 2010 PHC are Ewes, Akans, Ga-Adangbe and Guan with the dominant tribe being Ewe (98.2\%). In terms of religion, Christians form the majority of the population $(55.6 \%)$ while traditionalists constitute $33.5 \%$. Persons who profess no religion and other religions constitute $10 \%$ of the total population while Muslims constitute less than one percent $(0.9 \%)$ of the population.

The District has one hospital, a community private clinic, seven (7) health centres, four (4) Community based Health Planning and Service (CHPS) zones and one (1) RCH unit with an Adolescent Health Corner. There is one (1) college of education in the district, and a number of primary and second cycle schools.

Agriculture is the pillar of the economy of the Ketu North District. Farming is largely carried out on small-scale basis. The average acreage cultivated ranges from four to six acres for all crops. The District's irrigation potential remains largely untapped. Apart from the Afife Irrigation Project, there are numerous dams and dugouts which could be developed for use. The crop sector accounts for about 60 percent of agricultural activities in the District. The soil types favour the production of a variety of crops such as maize, cassava, sweet potato, cowpea and rice. Livestock and poultry production forms an integral part of animal production in the District. They serve as a means of storing wealth in times of bumper harvest of crops and provide cash reserves for emergencies and guarantees of food security in times of crop failures. The main animals reared in the District include cattle, sheep and goats, pigs, poultry and quite recently, grass cutters. 


\section{Study Population}

The study involved mothers/caregivers with children older than 6 months and less than two (2) years. Data was collected from only those who agreed and signed informed consent form. However, individuals who have not stayed in the municipality for the past 3 months before the day of the study were also excluded from the study, as well as Non-Ghanaians and Health professionals even if they have stayed in the municipality for the required period.

\section{Study Design}

A community-based descriptive cross-sectional study using quantitative method of data collection was used to collect data on adherence to Infant and young child feeding practices from mothers/caregivers in the district between January and March, 2017.

\section{Sample Size}

Five Hundred and Eighteen (518) participants were involved, this was determined using the formula: $\mathrm{n}=\mathrm{z}^{2} \times \mathrm{p}(\mathrm{q}) \div \mathrm{d}^{2}$ (Snedecor \& Cochran, 1989). Where $\mathrm{n}$ is the sample size to be determined, $\mathrm{z}$ is the $\mathrm{z}$-score (reliability coefficient) of 1.96 at $95 \%$ confidence level (C.L), $p$ is the estimated proportion of an attribute that was present in the population (prevalence of Exclusive breastfeeding 0.69) (KNHD, 2015), $\mathrm{d}$ is the desired level of precision 5\% (0.05), and $\mathrm{q}$ is $1-\mathrm{p}(0.31)$. Because of the involvement of cluster sample in the sampling method, 'design effect' was considered in the sample size calculation. Therefore, the sample size became n (328.69) multiplied by the 'design effect' (which was 1.5 in this case). For a $5 \%$ nonresponse rate of 493.04, the sample size was upwardly adjusted and rounded to 518 . This sample size ensured, with probability of $95 \%$ that the estimated prevalence fell within $\pm 5 \%$ of the true population coverage.

\section{Sampling method}

This study employed a multi-stage sampling technique. The district was stratified into four (4) strata. A sample size was proportionately allocated to each stratum based on the population size of the sub-districts. For each stratum, a list of all the communities were obtained and unique numbers were assigned to them. Five communities were selected using simple random sampling technique to represent each stratum. Based on the sample size calculated for each stratum and the total population of the communities selected, proportionate allocation was again used to allocate sample size to each community. The list of all houses in the selected communities were obtained and the number of houses needed based on the allocated sample size was randomly selected. In each selected house, 
mother/caregiver with children 0-24 months was identified and interviewed. In houses where there were more than one household, a balloting (YES or NO) was used to select one household to represent the house. Also, in households where there were more than one mother/caregiver with children 0-24 months, a balloting (YES or NO) was used to select one of them to represent the household. Those who picked YES were interviewed.

\section{Data collection}

A pre-tested semi-structured questionnaire, pen and paper was used to collect both demographic and infant and young child feeding practices data from study participants through face-to-face interview technique. Participants' ages were assessed using their Birth Certificates. Where certificates were not available, events calendar were used to determine their age.

\section{Ethical issues}

The study conformed to the required ethical guidelines regarding the use of humans, and was approved by the Ethical Review Committee of the Ghana Health Services, Research and Development Division, Accra with protocol number GHS-ERC 116/10/16. Participation in the study was voluntary, and consent and assent was sought from the participants and their guardians.

\section{Data analysis}

Data was entered using EPI DATA 3.1 software and then exported to STATA 12.1 for data entry and analysis respectively. After data had been entered, data cleaning and validation was done to ensure data quality before analysis was carried out. Descriptive statistics such as determination of percentages, frequencies, mean and standard deviation was used in describing the population. Chi-square test was used to assess the associations between the dependent and independent variables. A p-value <0.05 was considered as statistically significant.

Adherence to Infant and Young Child Feeding (IYCF) strategies was assessed based on these five practices; exclusive breastfeeding, complementary feeding, meal frequency, hygiene and sanitation, and consumption of variety of foods. Those who were found to be practicing these based on the age of the child were classified as adhering to IYCF strategies. 


\section{Results}

\section{Background Characteristics of Respondents}

A total of 518 participants were involved in the study, with majority $251(48.5 \%)$ of them between the ages of 25-28 years whiles those between the ages of 33-40 years were the least $27(5.2 \%)$. The mean age of mothers/caregivers and children were 25.6 years $( \pm 3.6 \mathrm{SD})$ and 9.8 months $( \pm 3.3 \mathrm{SD})$ respectively. All the participants had a form of formal education out of which 231 (44.6\%), 183 (35.3\%), and 104 (20.1\%) have had primary education, secondary education, and tertiary education respectively. More than half $271(52.3 \%)$ of the participants were single with regular partners, $148(28.6 \%)$ of them were co-habiting, $96(18.5 \%)$ were married and 3 $(0.6 \%)$ of them were single. Out of the ninety-six (96) participants that were married, $51(53.1 \%)$ were in a monogamous marriage and $45(46.9 \%)$ were in a polygamous marriage. Four hundred and nineteen (419) being $80.9 \%$ of the participants were Christians and the rest 99 (19.1\%) were Muslims. Also, $466(90.0 \%)$ of them were from Ewe ethnic background, while $40(7.7 \%)$ and $12(2.3 \%)$ were from Akan and Guan ethnicity respectively. Majority $461(89.0 \%)$ of the participants were involved in self-employed activities while $57(11.0 \%)$ were civil/public servants. Out of the 461 participants who were in self-employed activities, 82 (17.8\%), 133 (28.9\%), 131 (28.4\%) and $115(24.9 \%)$ were traders, Food Vendors, either Beauticians or Hair dressers, and Seamstresses respectively (Table 1).

Table 1. Background Characteristics of Respondents

\begin{tabular}{ccc}
\hline Variables & Frequency (518) & Percentage (\%) \\
\hline Age groups (mothers in years) & & \\
$17-20$ & 13 & 8.3 \\
$21-24$ & 251 & 25.9 \\
$25-28$ & 63 & 48.5 \\
$29-32$ & 27 & 12.2 \\
$33-40$ & & 5.2 \\
Age groups (children in months) & 163 & \\
$7-9$ & 166 & 31.5 \\
$10-12$ & 165 & 32.0 \\
$13-15$ & 11 & 31.9 \\
$16-18$ & 13 & 2.1 \\
$19-21$ & & 2.5 \\
Sex ( children) & 277 & \\
Male & 241 & 53.5 \\
Female & & 46.5 \\
Middle / JSS & 231 & \\
Secondary / SSS & 183 & 44.6 \\
Tertiary & 104 & 35.3 \\
Marital Status & & 20.1
\end{tabular}




$\begin{array}{ccc}\text { Single } & 3 & 0.6 \\ \text { Co-habiting } & 148 & 28.6 \\ \text { Single with regular partner } & 271 & 52.3 \\ \text { Married } & 96 & 18.5 \\ \text { Marriage Type } & & \\ \text { Monogamous } & 51 & 9.8 \\ \text { Polygamous } & 45 & 8.7 \\ \text { Religion } & & \\ \text { Christianity } & 419 & 80.9 \\ \text { Islam } & 99 & 19.1 \\ \text { Ethnicity } & & \\ \text { Ewe } & 466 & 90.0 \\ \text { Akan } & 40 & 7.7 \\ \text { Guan } & 12 & 2.3 \\ \text { Employment/occupation } & & \\ \text { Civil/Public Servant } & 57 & 11.0 \\ \text { Trader } & 82 & 15.8 \\ \text { Food Vender } & 133 & 25.7 \\ \text { Beautician/Hair Dresser } & 131 & 25.3 \\ \text { Seamstress } & 115 & 22.2\end{array}$

\section{Adherence to IYCF practices/strategies}

Out of the 518 participants for the study, only $45(8.7 \%)$ of them were found to be adhering to the IYCF practices/strategies. However, adherence on various strategies revealed that, 300 (57.9\%), 197 (38.0\%), 84 (16.2\%), $192(37.1 \%)$, and $172(33.2 \%)$ of the mothers/caregivers practiced exclusive breastfeeding, appropriate complementary feeding, observing hygiene and sanitation practices, given variety of foods, and following meal frequency respectively (Figure 1). 


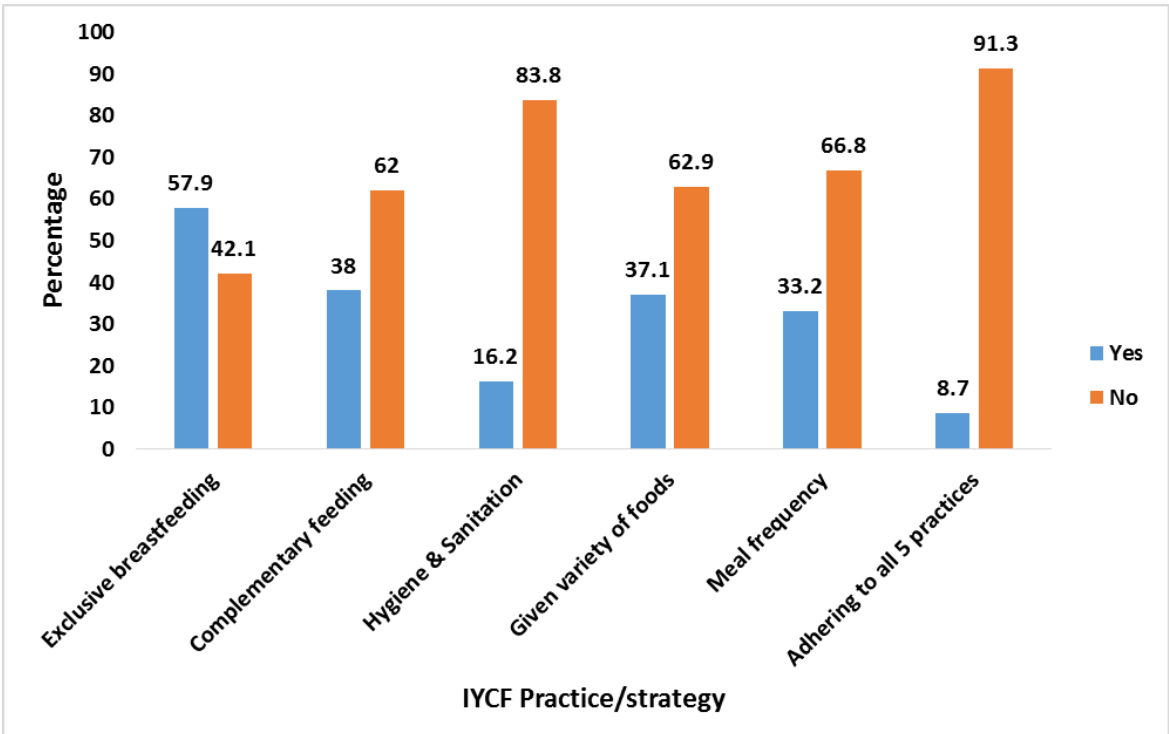

Figure 1. Mothers/caregivers adherence to Infant and Young Children Feeding practice/strategies.

\section{Associations between adherence to IYCF and background characteristics}

The results reveal a significant associations between adherence to IYCF practices/strategies and age of children $(p=.032)$, ethnicity $(p<.000)$, level of education $(p=.042)$ and employment status $(p=.041)$. To further examine the strength of associations, multiple logistic analysis was done to confirm associations between adherence to IYCF strategies and the explanatory variables. The analysis did not confirmed any strong associations between adherence to IYCF practice and the predictor variables. However, it did confirm associations between adherence to IYCF practices and Guan ethnic background [OR (7.82); CI (2.37 - 25.80)], Tertiary education (OR (0.13); CI (0.11 - 0.93)], food vending [OR (0.30); CI (0.10 $0.84)]$, hair dressing [OR $(0.30)$; CI $(0.11-0.85)$ ], children between $10-12$ months [OR (3.36); CI (1.54 - 7.33)], and children between 16-18 months [OR (4.26); CI (1.45 - 12.50)]. The associations showed that, Guans were 7.8 times more likely to adhere to IYCF practices than Ewes, whiles those with tertiary education were $87 \%$ less likely to follow IYCF strategies. It further indicated that food vendors and hair dressers were $70 \%$ less likely to adhere to IYCF practices than civil/public servants. Also, children between the ages of 10-12 months and 16-18 months were 3.7 and 4.3 times more likely to adhere to the feeding strategies respectively. In addition, when variables that were having associations with adherence to IYCF from bivariate analysis were alone tested for strength of associations, it was revealed that only hair dressing [AOR (0.24); CI (0.07-0.76)], Guan ethnic 
group [AOR (13.64); CI (3.43 - 54.25)], and tertiary education [AOR (0.28); CI (0.09-0.89)] were associated to IYCF strategies. Also, children between the ages of 10-12 months [AOR (3.44); CI (1.58 - 7.84)], 13-15 months [AOR (4.16; CI (1.14 - 12.16)], and 16-18 months [AOR (5.63) CI (1.76 17.99)] were having associations with IYCF practices. This also indicated that, hair dressers and those with tertiary education were $76 \%$ and $72 \%$ respectively less likely to adhere to IYCF practices than civil/public servants and those having middle/SSS education. Furthermore, it showed that, Guans (13.6 times), children between 10-12 months (3.4 times), 13-15 months (4.2 times) and 16-18 months (5.6 times) more likely to adhere to IYCF practices than Ewes and children between the ages of 7-9 months respectively (Table 2).

Table 1. Associations between adherence to IYCF and background characteristics

\begin{tabular}{|c|c|c|c|c|c|c|}
\hline \multirow[b]{2}{*}{$\begin{array}{c}\text { Demographic } \\
\text { variables }\end{array}$} & \multicolumn{2}{|c|}{ IYCF PRACTICES } & \multicolumn{2}{|c|}{$\begin{array}{l}\text { Pearson Chi- } \\
\text { Square }\end{array}$} & \multirow{2}{*}{$\begin{array}{l}\text { Adjusted } \\
\mathrm{OR}^{1}(95 \% \\
\text { CI })\end{array}$} & \multirow[b]{2}{*}{$\begin{array}{c}\text { Unadjusted } \\
\mathrm{OR}^{2}(95 \% \mathrm{CI})\end{array}$} \\
\hline & $\begin{array}{c}\text { Adherence } \\
\mathrm{n}=45(\%)\end{array}$ & $\begin{array}{c}\text { Non } \\
\text { Adherence } \\
\mathrm{n}=473(\%)\end{array}$ & $\mathrm{Chi}^{2}$ & $\begin{array}{c}\mathrm{P}- \\
\text { value }\end{array}$ & & \\
\hline \multicolumn{7}{|c|}{ Age of mothers (years) } \\
\hline $17-20$ & $5(11.1)$ & $38(8.0)$ & & & - & \\
\hline $21-24$ & & & & & $0.61(0.97-$ & \\
\hline & $10(22.2)$ & $124(26.2)$ & & & $1.90)$ & \\
\hline $25-28$ & $25(55.6)$ & $226(47.8)$ & 2.51 & 0.641 & $\begin{array}{c}0.84(0.30- \\
2.33)\end{array}$ & \\
\hline $29-32$ & $3(6.7)$ & $60(12.7)$ & & & $\begin{array}{c}0.38(0.09- \\
1.68)\end{array}$ & \\
\hline $33-40$ & $\begin{array}{c}2(4.4) \\
\text { (children) }\end{array}$ & $25(5.3)$ & & & $\begin{array}{c}0.61(0.11- \\
3.38)\end{array}$ & \\
\hline Male & $30(66.7)$ & $247(52.2)$ & & & - & \\
\hline Female & $15(33.3)$ & $226(47.8)$ & 3.45 & 0.062 & $\begin{array}{c}0.55(0.29- \\
1.04)\end{array}$ & \\
\hline \multicolumn{7}{|c|}{ Age of children (months) } \\
\hline $7-9$ & $16(35.5)$ & $147(31.1)$ & & & - & - \\
\hline $10-12$ & $13(28.9)$ & $153(32.3)$ & & & $\begin{array}{c}3.36(1.54- \\
7.33)\end{array}$ & $\begin{array}{c}3.44(1.58- \\
7.84)\end{array}$ \\
\hline $13-15$ & $9(20.0)$ & $156(33.0)$ & 12.59 & 0.032 & $\begin{array}{c}2.6(0.98- \\
7.38)\end{array}$ & $\begin{array}{c}4.16(1.14- \\
12.16)\end{array}$ \\
\hline $16-18$ & $3(6.7)$ & $8(1.7)$ & & & $\begin{array}{c}4.26(1.45- \\
12.50)\end{array}$ & $\begin{array}{c}5.63(1.76- \\
17.99)\end{array}$ \\
\hline $19-21$ & $4(8.9)$ & $9(1.9)$ & & & $\begin{array}{c}2.27(0.26- \\
19.51)\end{array}$ & $\begin{array}{c}2.30(0.25- \\
20.82)\end{array}$ \\
\hline \multicolumn{7}{|c|}{ Religion } \\
\hline Christianity & $39(86.7)$ & $380(80.3)$ & & & - & \\
\hline Islam & $6(13.3)$ & $93(19.7)$ & 1.06 & 0.30 & $\begin{array}{c}0.63(0.25- \\
1.53)\end{array}$ & \\
\hline
\end{tabular}




\begin{tabular}{|c|c|c|c|c|c|c|}
\hline Middle/JSS & $26(57.8)$ & $205(43.3)$ & \multirow{3}{*}{11.05} & \multirow{3}{*}{0.042} & - & - \\
\hline Secondary/SSS & $15(33.3)$ & $168(35.5)$ & & & $\begin{array}{c}0.70(0.36- \\
1.37)\end{array}$ & $\begin{array}{c}0.72(0.35- \\
1.49)\end{array}$ \\
\hline \multirow[t]{2}{*}{ Tertiary } & 4 (8.9) & $100(21.2)$ & & & $\begin{array}{c}0.13(0.11- \\
0.93)\end{array}$ & $\begin{array}{c}0.28(0.09- \\
0.89)\end{array}$ \\
\hline & \multicolumn{6}{|l|}{ Ethnicity } \\
\hline Ewe & 39 (86.7) & $427(90.3)$ & \multirow{3}{*}{18.44} & \multirow{3}{*}{$\begin{array}{c}< \\
0.000\end{array}$} & - & - \\
\hline Akan & $1(2.2)$ & $39(8.2)$ & & & $\begin{array}{c}0.28(0.04- \\
2.10)\end{array}$ & $\begin{array}{c}0.35(0.04- \\
2.79)\end{array}$ \\
\hline Guan & $5(11.1)$ & $7(1.5)$ & & & $\begin{array}{c}7.82(2.37- \\
25.80)\end{array}$ & $\begin{array}{c}13.64(3.43- \\
54.25)\end{array}$ \\
\hline \multicolumn{7}{|c|}{ Marital Status } \\
\hline Single & $1(2.2)$ & $2(0.4)$ & & & - & \\
\hline Co-habitng & $13(28.9)$ & 135 (28.6) & & & $\begin{array}{c}0.19(0.02- \\
2.27)\end{array}$ & \\
\hline Single with & & & 3.12 & 0.37 & $0.20(0.02-$ & \\
\hline regular partner & $25(55.6)$ & $246(52.0)$ & & & $\begin{array}{c}2.32) \\
0.13(0.05-\end{array}$ & \\
\hline Married & $6(13.3)$ & $90(19.0)$ & & & 1.70) & \\
\hline \multicolumn{7}{|c|}{ Employment } \\
\hline Civil Servant & $9(20.0)$ & $48(10.2)$ & & & - & - \\
\hline Trader & $8(17.7)$ & $74(15.6)$ & & & $\begin{array}{c}0.58(0.21- \\
1.60)\end{array}$ & $\begin{array}{c}0.69(0.23- \\
2.05)\end{array}$ \\
\hline Food Vendor & $7(15.6)$ & $126(26.6)$ & 10.32 & 0.041 & $\begin{array}{c}0.30(0.10- \\
0.84)\end{array}$ & $\begin{array}{c}0.34(0.12- \\
1.02)\end{array}$ \\
\hline Hair dresser & 7 (15.6) & $124(26.2)$ & & & $\begin{array}{c}0.30(0.11- \\
0.85)\end{array}$ & $\begin{array}{c}0.24(0.07- \\
0.76)\end{array}$ \\
\hline Seamstress & $14(31.1)$ & $101(21.4)$ & & & $\begin{array}{c}0.74(0.30- \\
1.82) \\
\end{array}$ & $\begin{array}{c}0.94(0.36- \\
2.50) \\
\end{array}$ \\
\hline
\end{tabular}

\section{Discussion}

In this study the coverage of exclusive breastfeeding among infants less than six months was $57.92 \%$ which is greater than the coverage (53\%) from a survey conducted in the district in the year 2013 but lesser than that of 2015 which is $69 \%$ (KNHD, 2016) which implies that there have been a decrease in adherence to IYCF practices. However, the exclusive breastfeeding coverage in this study was higher than a similar study using a cross sectional method conducted in Canada (13.8\%), Syria (12.9\%) and Sunsari district of Nepal (38\%) (Amanuel, 2015).

This study also aimed to examine the associations among maternal demographic factors: age, level of education, employment status and adherence to IYCF practices. It was realized that there was evidence of relationship between adherence to IYCF practice and age of children ( $p=$ $.032)$ and ethnicity of the mothers $(p<.000)$. The characteristics of mothers who exclusively breast fed their infants were 59.7\% among the age 25-28 years old group, a majority were self-employed (57.14\%), had middle education level (58.44\%). This study also found that not all the mothers that 
practiced exclusive breastfeeding, adhered to the proper IYCF recommendations. This finding was similar to a study conducted by (Ryan, Zhou, Ryan, \& Zhou, 2006) using a cohort study. This ethnic and age associations may be due to cultural beliefs and food taboos that prevent mothers and children from eating different kinds of food among many tribes and cultures in Ghana and Africa.

This study found that maternal age had no significant associations with adherence to IYCF practice which was in line with a similar finding of a study conducted by Lartey (2008) which also showed the same finding but using a different methodological approach for the sampling of participants. This finding also contradicted a similar study with a similar methodology conducted by Atchiri and Dako (2017) that higher coverage of proper IYCF practice were associated with maternal age (Atchibri \& Dako, 2017). A study conducted by Tan (2011) reported that younger age mothers tend not to exclusively breastfeed and this may be because they are more likely to engage in activities that make it difficult for them to breastfeed of which includes education and employment (Nkrumah, 2017) but this study shows no association of that sort. This could be as a result of different methodological approaches that has been used.

Yet, this study found that exclusive breastfeeding is significantly associated with maternal level of education. This finding contradicts previous studies conducted in Lebanon, Nigeria, and United States (Atchibri \& Dako, 2017). Amanuel, (2015) reported that mothers with higher education could be older than those with less education because of the time spent to acquire higher education, and that mothers with higher education are more likely to understand the benefits of breastfeeding than mothers with lower education (Amanuel, 2015) but this study shows that mothers with higher education are $87 \%$ less likely to adhere to IYCF practices in terms of initiation of complementary foods. Even though maternal education has been long recognized as one of the child survival strategies adopted by UNICEF (Lenggogeni, 2016). In contrast to this study, level of education has no association with exclusive breastfeeding (UNDP, 2002).

\section{Study limitations}

As any other studies, this study also has its own strengths and limitations. The use of pre tested questionnaires was the strengths of this study. However, the one week recall to determine feeding during illness practice means some infants who were sick months before were not provided for. This made it impossible to collect data on that component of IYCF practice. 


\section{Conclusion}

Upon all the nutrition education and counselling for mothers and caregivers in the district, the adherence to IYCF practices/strategies in this study was found to be unsatisfactory, though education is more likely to be associated with proper adherence to IYCF strategies than other demographic variables. Generally, mothers with primary and secondary education were found to be adhering to IYCF practices, while mothers with higher (postsecondary) education were not adhering to IYCF practices. This is contrary to the notion that higher maternal education is one of the child survival strategies.

\section{Recommendations}

1. Due to the low adherence to IYCF practices in the district, the District Health Management Team should intensify nutrition education and counselling focusing on the following areas;

$>\quad$ Practice of exclusive breastfeeding from birth to 6 months of age, and introduce complementary foods at 6 months of age (180 days) while continuing breastfeeding

$>\quad$ Continue frequent, on-demand breastfeeding until 2 years of age or beyond social care

Practicing of responsive feeding, applying the principles of psycho-

$>\quad$ Practicing of good hygiene and proper food handling

$>\quad$ Gradually increase food consistency, variety, and number of times as the infant gets older, adapting to the infant's requirements and abilities.

$>\quad$ Increase fluid intake during illness and after illness, including more frequent breastfeeding, and encouraging child to eat soft, varied, appetizing, favorite foods.

2. The District Health Management Team should integrate and intensify nutrition education and counselling into all existing reproduction and child health services and programs.

3. Mothers should be encouraged to report any breastfeeding challenges on time for it to be properly addressed.

4. All stakeholders should encourage fathers, other family members and significant others to provide the needed social support for mothers who are breastfeeding.

5. Further studies should be conducted to ascertain reasons why mothers are not adhering to IYCF strategies.

\section{References:}

1. Agbozo, F., Colecraft, E., \& Ellahi, B. (2015). Impact of type of child growth intervention program on caregivers' child feeding knowledge 
and practices : a comparative study in Ga West Municipality, Ghana. http://doi.org/10.1002/fsn3.318

2. Amanuel, T. (2015) Exclusive breastfeeding and associated factors.

3. Amuna, P., \& Zotor, F. B. (2008). Greenwich Academic Literature Archive ( GALA ) - the University of Greenwich open access repository trends and their impact in public health and human development Epidemiological and nutrition transition in developing countries: impact on human health and development. http://doi.org/10.1017/S0029665108006058

4. Atchibri, L. A., \& Dako, E. (2017). Factors associated with cessation of exclusive breastfeeding before six months among mothers in the Miramichi region ( Canada ), 6(1), 69-74. http://doi.org/10.9790/1959-0601046974

5. Bain, L. E., Awah, P. K., Geraldine, N., Kindong, N. P., Sigal, Y., Bernard, N., \& Tanjeko, A. T. (2013). Malnutrition in Sub - Saharan Africa: Burden, causes and prospects. Pan African Medical Journal, 15, 1-9. http://doi.org/10.11604/pamj.2013.15.120.2535

6. Bryce, J., Coitinho, D., Darnton-hill, I., Pelletier, D., Pinstrupandersen, P., Undernutrition, C., \& Group, S. (2008). Maternal and Child Undernutrition 4 Maternal and child undernutrition : effective action at national level, 65 $\square 81$. http://doi.org/10.1016/S01406736(07)61694-8

7. Federal, M. O. H. (2004). National Strategy For Infant And Young Child Feeding. Addis Ababa, Ethiopia.

8. Finance, D., \& Focused, N. (2016). Nutrition and Early Childhood Development in East and Southern Africa: A Snapshot of Equity Gaps and Opportunity, (August), 1-3.

9. Global Strategy for Infant and Young Child. (n.d.).

10. Grantham-mcgregor, S., Cheung, Y. B., Cueto, S., Glewwe, P., Richter, L., \& Strupp, B. (2007). Child development in developing countries 1 Developmental potential in the fi rst 5 years for children in, 369.

11. GSS (2012) 2010 population and housing census

12. Gupta, M. K., Mohapatra, A., Shivalli, S., \& Mishra, C. P. (2012). Nutritional estimates of school going children based on anthropometric measurements: study from a rural area of varanasi. Indian Journal of Community Health, 23(2), 58-59.

13. Lartey, A. (2008). Maternal and child nutrition in Sub-Saharan Africa: challenges and interventions. Proceedings of the Nutrition Society, 67(1), 105-108.

14. Lenggogeni, P. (2016). Examining Exclusive Breastfeeding Practice in Indonesia, and Its Association to Maternal Socio- Demographic 
Determinants, to Inform Intervention Efforts Aimed at Reducing Infant Mortality.

15. Lin, L. P., \& Dali, W. P. E. W. (2012). The impact of nutrition education interventions on the dietary habits of college students in developed nations: A brief review. Malaysian Journal of Medical Sciences, 19(1), 4-14.

16. Maxwell, D. (2012). Food Security and Its Implications for Political Stability: A Humanitarian Perspective, (September), 13-14.

17. Model, G., Pérez-escamilla, R., Curry, L., Minhas, D., Taylor, L., \& Bradley, E. (2015). Scaling Up of Breastfeeding Promotion Programs in Low- and Middle-Income Countries:, (3), 790-800. http://doi.org/10.3945/an.112.002873.790

18. Months, A., Saaka, M., Larbi, A., \& Hoeschle-zeledon, I. (2015). Factors Contributing To Positive Nutritional Deviance in the Growth of Children.

19. Nations, U., \& Unicef, F. (2013). Improving child nutrition: The achievable imperative for global progress.

20. Nkrumah, J. (2017). Maternal work and exclusive breastfeeding practice: a community based cross- sectional study in Efutu Municipal, Ghana, 1-9. http://doi.org/10.1186/s13006-017-0100-6

21. Oddy, W. H., Kendall, G. E., Blair, E., Klerk, N. H. De, Stanley, F. J., Landau, L. I., \& Silburn, S. (2003). Breast feeding and cognitive development in childhood: a prospective birth cohort study, 81-90.

22. Onis, M. De, \& Blössner, M. (2003). The World Health Organization Global Database on Child Growth and Malnutrition: methodology and applications, 518-526. http://doi.org/10.1093/ije/dyg099

23. Ramji, S. (2009). Impact of infant \& young child feeding \& caring practices on nutritional status \& health, (November), 624-626.

24. Ryan, A. S., Zhou, W., Ryan, A. S., \& Zhou, W. (2006). Lower Breastfeeding Rates Persist Among the Special Supplemental Nutrition Program for Women, Infants , and Children Participants , 1978 - 2003. http://doi.org/10.1542/peds.2005-1555

25. Satija, M., Sharma, S., Chaudhary, A., Kaushal, P., \& Girdhar, S. (2015). Original article Infant and young child feeding practices in a rural area of North India, 6(6), 60-65. http://doi.org/10.3126/ajms.v6i6.12067

26. Sika-bright, S. (2010). Socio-cultural factors influencing infant feeding practicies of mothers attending welfare clinic in Cape Coast, (January).

27. Srivastava, A., Mahmood, S. E., Srivastava, P. M., Shrotriya, V. P., \& Kumar, B. (2012). Nutritional status of school-age children-A scenario of urban slums in India. Archives of Public Health, 70(1), 8. 
28. Tan, K. L. (2011). Factors associated with exclusive breastfeeding among infants under six months of age in peninsular malaysia. International Breastfeeding Journal, 6(1), 2. http://doi.org/10.1186/1746-4358-6-2

29. The health sector in ghana facts and figures. (2010).

30. UNDP. (2002). Handbook on Monitoring and Evaluating for Results. Knowledge Creation Diffusion Utilization, (January), 1996-1996. Retrieved from http://www.undp.org/eo/documents/HandBook/MEHandBook.pdf

31. Union, A., \& Africaine, U. (2009). African union union africaine.

32. UNICEF. (2016). The State of the World's Children 2016. A fair chance for every child. Retrieved from http://www.unicef.org on $5^{\text {th }}$ June, 2017.

33. World Health Organization. (2010). Technical Guidelines for Integrated Disease Surveillannce and Response in the African Region, 1-416. 